Психология. Журнал Высшей школы экономики.

2018. T. 15. № 3. C. 491-509. DOI: 10.17323/1813-8918-2018-3-491-509

\title{
ВАЛИДИЗАЦИЯ РУССКОЯЗЫЧНОЙ ВЕРСИИ ОПРОСНИКА ЭТИЧЕСКИХ ПОЗИЦИЙ
}

\begin{abstract}
А.А. ФЕДОРОВ ${ }^{\mathrm{a}}$, И.В. БАДИЕВ
${ }^{2}$ Новосибирский государственньй университет, 630090, Россия, Новосибирск, ул. Пирогова, д. 1

${ }^{5}$ Бурятский государственный университет, 670000, Россия, Улан-Удэ, ул. Смолина, д. 24 «»

Резюме

В статье представлены результаты валидизации русскоязычной версии опросника этических позиций Д.Р. Форсайта (Ethics Position Questionnaire, EPQ). Оригинальная версия опросника содержит два ортогональных фактора (Идеализм и Релятивизм), на основе которых составлена таксономия этических позиций (ситуационизм, абсолютизм, суб́ъективизм и эксепционизм). В статье высказано предположение, что идеализм и релятивизм следует рассматривать как поведенческие диспозиции. В настоящем исследовании при помощи конфирматорного факторного анализа проверены несколько теоретических моделей. КФА показал, что наибольшей пригодностью обладает двухуровневая структурная модель, в которой идеализм и релятивизм являются ортогональными факторами второго порядка. При этом идеализм включает в себя такие факторы, как Недопущение вреда (И1) и Забота о благе (И2), а релятивизм - Относительность этических систем (P1), Межличностный релятивизм (Р2) и Допустимость лжи (Р3). Полученная модель обладает рядом преимуществ. Во-первых, она полностью соответствует теоретической модели Д.Р. Форсайта, включая ортогональность основных факторов. Во-вторых, она предполагает многомерность конструктов «идеализм» и «релятивизм». В-третьих, позволяет согласовать между собой результаты предыдущих әмпирических исследований. Также в исследовании установлено, что EPQ имеет хорошую внутреннюю согласованность, ретестовую надежность, конвергентную, дискриминантную и номологическую валидность. Последняя оценивалась в рамках номологической сети, в которой идеализм и релятивизм были соотнесены с конструктами, связанными с ценностной системой человека (в рамках теории базовых индивидуальных ценностей Ш. Шварца). Полученные результаты позволяют считать русскоязычную версию ЕРQ надежным и валидным инструментом оценки идеализма и релятивизма.
\end{abstract}

Ключевые слова: этические позиции, идеализм, релятивизм, мораль, диспозиция.

В современной психологии наблюдается устойчиво растущий интерес к моральным аспектам поведения человека. На современном этапе можно утверждать, что психология морали оформилась в самостоятельную междисциплинарную научную область со специфическим предметом исследования. Одной из наиболее актуальных проблем изучения в данной области являются индивидуальные различия в вынесении моральных суждений.

Работа выполнена при финансовой поддержке РФФИ в рамках научного проекта № 18-013-00715. 
Одна из современных теорий, делающих акцент на индивидуальной вариативности моральных суждений, была сформулирована американским психологом Д. Форсайтом (Forsyth, 1980). В ее рамках индивидуальные различия в области морали объясняются интуитивными этико-философскими идеологиями, присущими личности, которые формируются в результате социализации и приобретения жизненного опыта. Д. Форсайт рассматривает индивида в качестве интуитивного этического философа, который выносит моральные суждения, основываясь на личных представлениях о добре и зле. Данные этические представления формируются в результате жизненного опыта в решении различных этических проблем.

Д. Форсайт признает, что индивидуальные этико-философские системы могут иметь достаточно сложную структуру и включать в себя множество элементов. Тем не менее для подавляющего большинства людей при вынесении морального суждения прослеживаются две номотетические закономерности: озабоченность последствиями и озабоченность принципами. Таким образом, Д. Форсайт предложил описывать интуитивные идеологические пристрастия личности при помощи двух ортогональных факторов: идеализма и релятивизма. В качестве измерительных шкал они образуют два дихотомических континуума. В итоге каждый индивид может быть отнесен к одной из четырех групп этических позиций по степени выраженности релятивизма и идеализма.

Релятивизм определяется как установка индивида на то, что твердых моральных принципов не существует. При оценке других люди с высоким уровнем релятивизма большее значение придают обстоятельствам, а не нарушенным моральным законам. Индивиды с низким уровнем релятивизма (универсализм), напротив, убеждены в существовании абсолютных, незыблемых нравственных норм, этических заповедей, моральных императивов.

Идеализм определяется как степень убежденности индивида в том, что «правильные» действия всегда приводят к желаемым последствиям. Индивиды с высоким уровнем идеализма выносят моральные суждения, основываясь на последствиях действий. Морально то, что приносит благо, аморально то, что приносит вред. При этом мотивы совершения поступка в расчет не принимаются, для вынесения морального суждения важны лишь последствия как таковые. Другими словами, идеалисты верят в то, что «правильные» поступки приносят благо для всех. Индивиды с низким уровнем идеализма (прагматизм) убеждены в том, что любой поступок приносит как пользу, так и вред и любое действие сопряжено с сопутствующим ущербом. Таким образом, вынесение морального суждения о поступке на основе его последствий невозможно, поскольку человек, совершая тот или иной выбор, выбирает «из двух зол».

Пересечение факторов идеализма и релятивизма дает таксономию этических позиций (таблица 1).

Абсолютизм. Индивиды с высоким уровнем идеализма и низким уровнем релятивизма при вынесении моральных суждений опираются на универсальные моральные принципы. Абсолютисты полагают, что следование твердым этическим принципам помогает достичь наилучшего результата. Сталкиваясь 
Таксономия әтических позиций Д. Форсайта

\begin{tabular}{|c|c|c|}
\hline \multirow{2}{*}{ Идеализм } & \multicolumn{2}{|c|}{ Релятивизм } \\
\hline & Высокий & Низкий \\
\hline Высокий & $\begin{array}{l}\text { Ситуационизм. Отвержение нрав- } \\
\text { ственных правил; одобрение инди- } \\
\text { видуального анализа каждого акта } \\
\text { в каждой конкретной ситуации }\end{array}$ & $\begin{array}{l}\text { Абсолютизм. Наилучший возможный } \\
\text { результат всегда достигается за счет } \\
\text { следования универсальным моральным } \\
\text { правилам }\end{array}$ \\
\hline Низкий & $\begin{array}{l}\text { Суббективизм. Этическая оценка } \\
\text { основана на личных ценностях, а } \\
\text { не универсальных моральных } \\
\text { принципах }\end{array}$ & $\begin{array}{l}\text { Эксепционизм. Моральные абсолюты } \\
\text { являются руководством в моральных } \\
\text { суждениях, но они открыты для праг- } \\
\text { матических, утилитарных исключений }\end{array}$ \\
\hline
\end{tabular}

с этической дилеммой, абсолютист принимает решение, исходя из предписаний, не делая исключений, не учитывая контекста ситуации или последствий. В качестве иллюстрации Д. Форсайт приводит пример врача, перед которым стоит дилемма - соврать или сказать правду пациенту о его состоянии здоровья и перспективах лечения. Абсолютист разрешает данную дилемму, исходя из положения о том, что «ложь - это плохо», независимо от того, принесет ли она пользу в обозримом будущем или нет.

Эксепционизм. Индивиды с низким уровнем релятивизма и низким уровнем идеализма при вынесении моральных суждений опираются на моральные абсолюты, однако признают, что «во всех правилах есть исключения». В рамках эксепционизма моральность оценивается, исходя из наибольшего блага для большинства людей. Так, в примере с дилеммой врача эксепционист предлагает взвесить возможный вред от лжи с возможной пользой. В том случае, если последствия лжи приносят наибольшее благо по сравнению с правдой, то с этических позиций ложь предпочтительней.

Ситуационизм. Индивиды с высоким уровнем релятивизма и высоким уровнем идеализма при вынесении моральных суждений полагают, что каждый конкретный случай должен быть рассмотрен в индивидуальном порядке. Вынесение морального суждения основывается не на оценке поступка как «хорошего» или «плохого», а исходя из его «контекстной уместности». Таким образом, этичность определяется полезностью, исходя из последствий действия, без учета мотивов и намерений.

Субъективизм. Индивиды с высоким уровнем релятивизма и низким уровнем идеализма, как и ситуационисты, полагают, что моральные принципы относительны, поэтому при вынесении морального суждения основываться на них не следует. Но в отличие от ситуационистов в своих суждениях не полагаются и на последствия, поскольку не верят во «всеобщее благо». А поскольку всеобщее благо недостижимо, то индивид должен ориентироваться исключительно на собственные интересы. Таким образом, моральные суждения выносятся относительно того, насколько действия человека соответствуют его собственным интересам. 
Следует отметить, что в теории этических позиций Д. Форсайта интуитивные этические идеологии не имеют иерархических отношений и, следовательно, данная таксономия Д. Форсайта не позволяет говорить о предпочтительности одного способа вывода моральных суждений над другим.

На основе вышеизложенной концепции Д. Форсайтом был разработан опросник этических позиций (Ethics Position Questionnaire), «измеряющий» идеализм и релятивизм ${ }^{1}$. В настоящей статье представлены результаты апробации и валидизации русскоязычной версии этого опросника - проверки его факторной структуры, оценки внутренней согласованности, ретестовой надежности, конвергентной, дискриминантной и номологической валидности. Оценка последней осуществлялась путем построения номологической сети между идеализмом, релятивизмом и конструктами, связанными с ценностной сферой человека. Анализ ценностных конструктов проводился в рамках теории базовых индивидуальных ценностей Ш. Шварца, одной из наиболее распространенных теорий в этой области (Шварц и др., 2012). В ее рамках базовые индивидуальные ценности определяются направленностью на 1) личную/социальную выгоду; 2) рост и саморазвитие/избегание тревоги и защиту; 3) открытость к изменениям/сохранение статус-кво; 4) собственное благо/благо других. Таким образом, ценности, связанные с благом и выгодой для других (группы), должны иметь положительную связь с идеализмом как шкалой, измеряющей заботу о благе и избегание вреда. К ним относятся, в первую очередь, такие ценности первого порядка, как благожелательность и универсализм, а также такая ценность второго порядка, как самопреодоление. Можно также ожидать наличия связи идеализма с конформизмом, поскольку последний в рамках теории Ш. Шварца включает в себя избегание причинения вреда другим людям. Убежденность в отсутствии абсолютных моральных норм, или релятивизм, предполагает направленность на изменения и стремление к свободе от ограничений, что соответствует таким ценностям первого порядка, как самостоятельность и стимуляция, а также такой ценности второго порядка, как открытость к изменениям. Таким образом, на основе теории Д.Р. Форсайта, лежащей в основе EPQ, и теории базовых индивидуальных ценностей Ш. Шварца были сформулированы следующие гипотезы:

Н1. Идеализм положительно связан с ценностью благожелательности.

Н2. Идеализм положительно связан с ценностью универсализма.

\footnotetext{
Отметим, что большую распространенность данный опросник получил в области изучения этических аспектов поведения в бизнесе. Приведем для примера результаты двух исследований. Дуглас и Вир показали, что высокий идеализм отрищательно связан с применением сомнительной тактики бюджетного люфта, которая заключается в умьшленной недооценке доходов и переоценке расходов для демонстрации перевыполнения прогноза в будущем (Douglas, Wier, 2005). Карандэ с соавт. проследили связь идеализма с приверженностью корпоративным ценностям, в то время как релятивизм, напротив, связан с их негативной оценкой (Karande et al., 2002) Также получены данные, касающиеся кросс-культурных различий в әтических позициях, их связи с различными параметрами культурных измерений (в рамках теории Г. Хофстеде), ценностями и пр. (Forsyth et al., 2008).
} 
Н3. Идеализм положительно связан с ценностью конформности.

H4. Идеализм положительно связан с ценностью самопреодоления (ценность второго порядка).

H5. Релятивизм положительно связан с ценностью самостоятельности.

H6. Реляятивизм положительно связан с ценностью стимуляции.

H7. Релятивизм положительно связан с ценностью открытости к изменениям (ценность второго порядка).

\section{Методика}

Выборка. В исследовании принял участие 241 человек в возрасте от 17 до 27 лет $(\mathrm{M}=20.75, \mathrm{Me}=20, \mathrm{SD}=1.98), 106$ мужчин и 135 женщин, студенты различных факультетов НГУ. Из них 108 человек (40 мужчин, 68 женщин) прошли процедуру ретеста через 4 недели после основного тестирования.

Подвыборки по использованным методикам: опросник этических позиций $(\mathrm{EPQ})$ - 241 чел., портретный опросник ценностей (PVQ-R2) - 136 чел., шкала социальной желательности Кроуна-Марлоу - 60 чел.

\section{Инструменты}

1. Опросник этических позиций (EPQ) Д.Р. Форсайта создан для измерения идеализма и релятивизма и состоит из 20 пунктов, по 10 на каждую из шкал (Forsyth, 1980). В оригинальной статье испытуемым необходимо оценить степень согласия с каждым утверждением по 9-балльной шкале от «полностью не согласен» (1) до «полностью согласен» (9). Подсчитывается сумма баллов, которую набрал испытуемый по каждой из шкал, что делает возможным отнесение человека к одной из четырех категорий: ситуационисты, абсолютисты, эксепционисты, субъективисты.

В настоящем исследовании для валидизации на российской выборке использовалась русскоязычная версия EPQ, разработанная А.А. Фёдоровым и И.В. Бадиевым². Для ее создания применялся метод обратного перевода. Уточнение перевода проводилось с участием носителей языка. Текст методики и ключ с разрешения Д.Р. Форсайта приведены в приложении к статье.

Также в русскоязычной версии, по рекомендации Д.Р. Форсайта, 9-балльная шкала ответов была заменена на 5-балльную. Практика использования англоязычной версии EPQ показала, что 5-балльная шкала Ликерта обладает

\footnotetext{
${ }^{2}$ В литературе имеются сведения об использовании EPQ на российской выборке (Robertson et al., 2003; Sommer et al., 2000). В әтих исследованиях, однако, как указывает сам Д.Р. Форсайт (личная коммуникация), не проводилась валидизация русскоязычной версии $\mathrm{EPQ}$ и из психометрических характеристик приведены только данные, касающиеся внутренней согласованности. Кроме того, по неясным причинам в одном из исследований шкала релятивизма включала в себя только 9 пунктов (Robertson et al., 2003). По всей видимости, в двух вышеуказанных исследованиях использовались разные переводы. Для решения задач настоящего исследования все пункты переводились заново.
} 
достаточной чувствительностью. Кроме того, результаты некоторых исследований свидетельствуют о том, что при использовании шкал типа «согласен не согласен» 5-балльный вариант является предпочтительным по сравнению с более мерными вариантами, поскольку последние могут приводить к получению данных более низкого качества (Revilla et al., 2014).

2. Портретный опросник иенностей (2-я пересмотренная версия, PVQ-R2) использовался для проверки номологической валидности EPQ. Он включает 57 пунктов и позволяет оценить 19 ценностей, которые могут быть сведены к 10 базовым ценностям, выделенным Ш. Шварцем, и 4 ценностям второго порядка (Шварц и др., 2012). Для каждого утверждения респондент указывает, насколько описываемый человек похож на него.

3. Поскольку отмечается, что в рамках проверки дискриминантной валидности необходимо анализировать смещение ответов, которое может быть вызвано социальной желательностью, анализ связей создаваемой или адаптируемой методики со шкалой социальной желательности является общей исследовательской практикой (Campbell, Fiske, 1959; Paulhus, 1991). В нашем исследовании в этих целях использовалась методика Марлоу-Крауна для исследования мотивации одобрения в адаптации Ю.Л. Ханина (1976). Она представляет собой сокрашенную версию оригинальной шкалы социальной желательности Марлоу-Крауна и содержит 20 пунктов, с каждым из которых респондент должен согласиться или не согласиться.

\section{Результаты}

\section{Факторная структура EPQ}

Для анализа факторной структуры EPQ проводился конфирматорный факторный анализ в статистическом пакете EQS 6.2 for Windows. Учитывая предыдущие исследования, проверялись три теоретические модели. Модель 1 является двухфакторной и соответствует исходным теоретическим положениям Форсайта (1980). Она представлена двумя не коррелирующими друг с другом факторами (Идеализм и Релятивизм), каждый из которых включает в себя по 10 пунктов. Модель 2 получена в исследовании Дэвиса с соавт. (Davis et al., 2001) и состоит из трех факторов: идеализм (10 пунктов), релятивизм (8 пунктов) и правдивость (2 пункта, выделенные из первичной шкалы релятивизма). Фактор «правдивость» коррелирует с фактором релятивизма. В исследованиях Дэвиса с соавт. эта модель продемонстрировала большее соответствие эмпирическим данным, нежели оригинальная двухфакторная модель Форсайта. Модель 3 была получена в кросс-культурных исследовании на выборках Австрии, Великобритании, Брунея и США (Cui et al., 2005). Как и Модель 1, она является двухфакторной, но в ней на каждый фактор приходится не по 10, а по 6 пунктов (1-6 для шкалы идеализма и 3-8 для шкалы релятивизма).

Поскольку анализ показал, что распределение переменных отклоняется от многомерной нормальности (c.r. = 18.1), конфирматорный факторный анализ 
проводился с поправкой Саторры-Бентлера (Satorra, Bentler, 1994). Для оценки пригодности моделей использовались следующие показатели: 1) SatorraBentler (S-B) $\chi^{2}, p>0.05 ; 2$ ) RMSEA $<0.05$ (при 90\% CI от 0.000 до 0.049); 3) CFI $>0.95$; 4) IFI $>0.95 ; 5)$ TLI $>0.95$. Результаты проверки трех моделей представлены в таблице 2.

Двухфакторная Модель 1 продемонстрировала неприемлемый уровень соответствия эмпирическим данным: (S-B) $\chi^{2}=432.34, p<0.001$; RMSEA $=0.080$ (при $90 \%$ СІ от 0.071 до 0.089); CFI = 0.793; IFI =0.796; TLI =0.769.

Показатели трехфакторной Модели 2 оказались лучше: (S-B) $\chi^{2}=277,30$, $p<0.001 ;$ RMSEA $=0.052$ (при $90 \%$ CI от 0.040 до 0.062); CFI $=0.916$; IFI $=$ 0.914; TLI = 0.904. Двухфакторная Модель 3 также показала лучшее соответ ствие эмпирическим данным, чем Модель 1 , ее сравнительные индексы пригодности (CFI, IFI и TLI) статистически значимо не отличаются от показателей Модели $2^{3}$. Укажем, что и Модель 2, и Модель 3 , за исключением (S-B) $\chi^{2}$, удовлетворяют «мягким» критериям соответствия: RMSEA < 0.08 ; CFI, IFI, TLI $>0.90^{4}$.

Можно отметить, что апостериорная модификация моделей на основе индексов Лагранжа позволяет повысить уровень соответствия Моделей 2 и 3. Однако подобная модификация, связанная с допущением ковариации ошибок, - это хотя и распространенная, но сомнительная практика, для которой мало теоретических оснований (Hermida, 2015), поэтому нами было предпринято дополнительное теоретическое исследование, направленное на получение такой структуры опросника, которая бы, во-первых, удовлетворяла жестким критериям соответствия без ковариации ошибок и, во-вторых, соответствовала оригинальной двухфакторной теории Форсайта.

С учетом предшествуюших исследований (Cui et al., 2005; Davis et al., 2001; Forsyth et al., 2008; Redfern, 2004), проведенного структурного анализа трех конкурирующих моделей и содержания пунктов, входящих в EPQ, была создана двухуровневая структурная модель с двумя ортогональными факторами второго порядка (Идеализм и Релятивизм).

Таблица 2

Показатели соответствия моделей по итогам СFА

\begin{tabular}{|l|c|c|c|c|c|}
\hline \multicolumn{1}{|c|}{ Модель } & $\mathbf{( S - B )} \chi^{2}, \mathbf{p}$ & RMSEA [90\% CI] & CFI & IFI & TLI \\
\hline М.1 (Форсайт) & $432.34, p<0.001$ & $0.080[0.0710 .089]$ & 0.793 & 0.796 & 0.769 \\
\hline М.2 (Дэвис и др.) & $277.30, p<0.001$ & $0.052[0.0400 .062]$ & 0.916 & 0.914 & 0.904 \\
\hline М.3 (Цуи и др.) & $125.36, p<0.001$ & $0.074[0.0670 .091]$ & 0.918 & 0.919 & 0.900 \\
\hline
\end{tabular}

${ }^{3}$ Отметим, что прямое сопоставление индексов пригодности Модели 3 с Моделями 1 и 2 невозможно, поскольку они включают в себя разное количество переменных.

${ }^{4}$ Ужесточение критериев (RMSEA < 0.05; CFI, IFI, TLI > 0.95) связывают с исследованием Ху и Бентлера (Hu, Bentler, 1999), но и они сами, и другие ученые указывают на возможные ограничения применимости этих рекомендаций (Marsh et al., 2004). 
Как показало кросс-культурное исследование Цуи с соавт., в шкале идеализма можно выделить два вида пунктов. В фокусе первых находится концепция снижения вреда и риска, в фокусе вторых - сохранение и преумножение блага (Cui et al., 2005, p. 67). Цуи с соавт. предпочли оставить в шкале идеализма только первый вид пунктов, исключив второй. На наш взгляд, обе эти концепции содержательно входят в фактор идеализма, образуя две его грани.

С другой стороны, из фактора релятивизма Дэвис с соавт. выделили, как уже указывалось, фактор правдивости, или, точнее, допустимости лжи. Они рассматривали их как факторы одного порядка, в то время как мы полагаем, что допустимость лжи должна входить в общий фактор релятивизма как более узкая концепция. В то же время проведенный ранее конфирматорный факторный анализ (в котором допускалась ковариация ошибок) показал, что пункты 16-18 с высокой долей вероятности входят в общую латентную переменную. Анализ этих пунктов позволяет выделить в них общее содержание, связанное с релятивизмом в межличностных отношениях (например, такой пункт, как «Жесткая этическая позиция, которая запрецает определеннье виды поступков, препятствует достижению лучиих отноиений между людьми и их приспособлению друг к другу»). Оставшиеся пункты шкалы релятивизма связаны с концепцией относительности этических систем (например, пункты «Нет таких этических принципов, которые настолько важны, что должны быть частью любого этического кодекса» или «Разные системь моральных принципов нельзя сравнивать в отноиении правильности»).

Таким образом, мы предположили, что EPQ состоит из пяти факторов первого порядка, которые образуют два ортогональных фактора второго порядка, что согласуется с концепцией Д.Р. Форсайта.

Полученная модель проверялась методом конфирматорного факторного анализа без допущения ковариации ошибок и с поправкой Саторры-Бентлера (ковариация между вторичными факторами с учетом проверяемой теоретической модели зафиксирована на 0). Результаты конфирматорного анализа показывают, что эта модель отлично соответствует эмпирическим данным: $(\mathrm{S}-\mathrm{B}) \chi^{2}=185.33, p=0.111$; RMSEA $=0.024$ (при $90 \%$ CI от 0.000 до 0.039); $\mathrm{CFI}=0.982 ; \mathrm{IFI}=0.983 ; \mathrm{TLI}=0.979$.

Структурная двухуровневая модель EPQ представлена на рисунке 1.

Таким образом, нами получена и успешно проверена на соответствие эмпирическим данным двухуровневая структура EPQ, которая обладает следующими преимуществами:

1) полностью соответствует теоретической модели Д.Р. Форсайта, включая ортогональность основных факторов (при добавлении связи между ними, т.е. свободном вычислении ковариации, пригодность модели статистически значимо снижается, хотя и остается на хорошем уровне: $(\mathrm{S}-\mathrm{B}) \chi^{2}=185.33, p=0.014$ RMSEA $=0.033$ (при $90 \%$ СI от 0.015 до 0.046 ); CFI $=0.967 ; \mathrm{IFI}=0.968 ; \mathrm{TLI}=$ $=0.961)$;

2) предполагает многомерность конструктов «идеализм» и «релятивизм»;

3) позволяет согласовать между собой результаты предыдущих эмпирических исследований. 
Структурная модель ЕPQ: стандартизованное решение

Рисунок 1 (параметры ошибок не показаны)

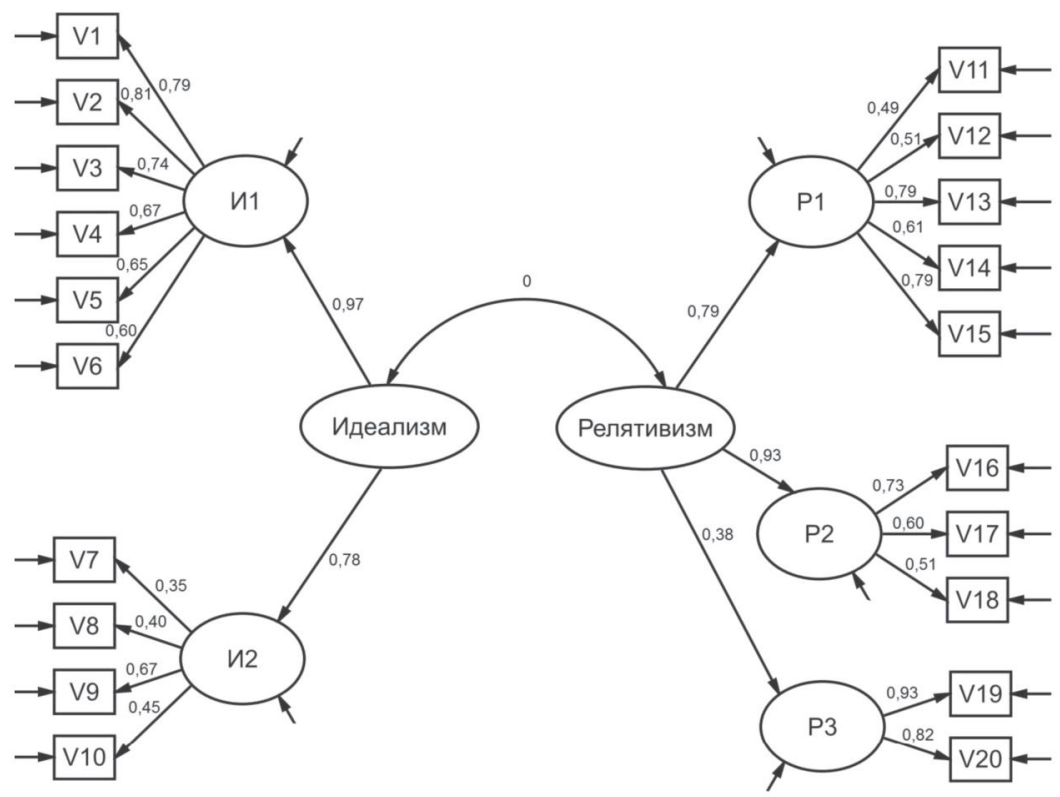

Примелание. Для переменных приведены номера пунктов оригинального опросника. И1 Недопущение вреда; И2 - Забота о благе; Р1 - Относительность этических систем; Р2 Межличностный релятивизм; Р3 - Допустимость лжи.

\section{Надежность шкал EPQ}

В исследовании оценивались два класса надежности: надежность по внутренней согласованности и ретестовая надежность. В статье, посвященной адаптации опросника Темная дюжина, авторы вслед за зарубежными исследователями справедливо указывают на то, что в ряде случаев традиционный коэффициент $\alpha$ Кронбаха не является оптимальной мерой внутренней согласованности (Корнилова и др., 2015). Следуя рекомендациям сообщать в исследовании и о других мерах внутренней согласованности, помимо $\alpha$ (Dunn et al., 2014; Revelle, Zinbarg, 2008), мы также измеряли коэффициент составной надежности (коэффициент $\omega$ Макдональда). Коэффициент $\alpha$ вычислялся в программном пакете Statsoft STATISTICA 8.0, коэффициент $\omega-$ согласно формуле в терминах факторных нагрузок, при этом факторы первого порядка рассматривались как индикаторы (Geldhof et al., 2014). Результаты анализа приведены в таблице 3.

Приведенные данные свидетельствуют о хорошей внутренней согласованности шкал и подшкал EPQ. Полученные данные в целом соответствуют результатам зарубежных исследований. Форсайт, например, приводит следующие 
Коэффициенты $\alpha$ и ш для пшкал ЕPQ

\begin{tabular}{|l|c|c|c|c|}
\hline \multicolumn{1}{|c|}{ Шкала } & $\boldsymbol{\alpha}$ Кронбаха & ш Макдональда & $\mathbf{M}$ & $\mathbf{S D}$ \\
\hline Идеализм & 0.834 & 0.871 & 33.91 & 6.52 \\
\hline Релятивизм & 0.806 & 0.764 & 33.74 & 6.63 \\
\hline
\end{tabular}

показатели $\alpha$ Кронбаха: 0.80 для шкалы идеализма и 0.73 для шкалы релятивизма (Forsyth, 1980).

Ретестовая надежность оценивалась при помощи коэффициента корреляции Пирсона между данными двух опросов $(\mathrm{N}=108)$, проведенных с интервалом в четыре недели $0.75, p<0.01$; для шкалы релятивизма $-0.72, p<0.01$. Эти коэффициенты свидетельствуют о достаточной устойчивости во времени шкал ЕPQ. В оригинальном исследовании Форсайта интервал ретеста составил две недели, а полученные показатели $r=0.67$ для шкалы идеализма и $r=0.66$ для шкалы релятивизма (Ibid.).

\section{Конвергентная и дискриминантная валидность икал $E P Q$}

Конвергентная и дискриминантная валидность шкал EPQ оценивалась в рамках подхода Форнелла-Ларкера (Fornell, Larcker, 1981). В нем конвергентная, дискриминантная, номологическая и очевидная валидность представляют собой компоненты конструктной валидности, являющейся мерой того, насколько набор измеряемых переменных действительно отражает содержание теоретического латентного конструкта. На основе результатов CFA ортогональной двухуровневой модели EPQ определялись следующие параметры: $\mathrm{AVE}, \mathrm{CR}, r_{\mathrm{AB}}$. В качестве критериев конвергентной валидности, которая связана с оценкой общности дисперсии переменных латентного конструкта, брались следуюшие значения: AVE $>0.50, \mathrm{CR}>0.70$, CR $>$ AVE. В качестве критериев дискриминантной валидности, связанной с оценкой того, насколько один конструкт отличается от других, брались следующие значения: для любых двух факторов $\mathrm{A}$ и $\mathrm{B} \mathrm{AVE}_{\mathrm{A}}>r_{\mathrm{AB}}^{2}, \mathrm{AVE}_{\mathrm{B}}>r_{\mathrm{AB}}{ }^{2}$ (Hair et al., 2014). Результаты анализа приведены в таблице 4.

Из приведенных данных видно, что двухуровневая ортогональная модель EPQ удовлетворяет критериям конвергентной и дискриминантной валидности․

\footnotetext{
${ }^{5}$ Здесь и далее мы использовали параметрические критерии, несмотря на то, что распределение данных в нашем исследовании отличается от нормального. Зарубежные и отечественные исследователи указывают, что эти критерии относительно устойчивы к нарушению нормальности, особенно при больших N, и их применение остается корректным (Norman, 2010; Корнилова и др., 2015; Лемешко, Лемешко, 2008).

${ }^{6}$ Поскольку проверялась ортогональная модель СFА, $r_{\mathrm{AB}}=0$. Заметим, что проверка модели со свободным вычислением ковариации между факторами второго порядка приводит к схожим результатам. В ней $r_{\mathrm{AB}}^{2}=0.02, \mathrm{AVE}_{\mathrm{VI}}=0.762, \mathrm{AVE}_{\mathrm{P}}=0.537, \mathrm{CR}_{\mathrm{II}}=0.864, \mathrm{CR}_{\mathrm{P}}=0.760$.
} 
AVE, CR, $r_{\text {Ав }}{ }^{2}$ шкал EPQ

\begin{tabular}{|l|c|c|c|}
\hline \multicolumn{1}{|c|}{ ІІкала } & AVE & $\mathbf{C R}$ & \multirow{2}{*}{$\boldsymbol{r}_{\mathrm{AB}}{ }^{2}$} \\
\cline { 1 - 3 } Идеализм & 0.772 & 0.871 & 0 \\
\hline Релятивизм & 0.544 & 0.764 & \\
\hline
\end{tabular}

В рамках проверки дискриминантной валидности проверялась связь шкал EPQ с социальной желательностью $(\mathrm{N}=60)$. Низкие значения корреляционных связей при этом позволяют говорить о том, что содержание пунктов, входящих в шкалу, не смешано с социальной желательностью (Paulhus, 1991). В нашем исследовании для шкалы идеализма эта связь составила $r=0.21, p>0.05$; для шкалы релятивизма $r=0.16, p>0.05$, что свидетельствует в пользу дискриминантной валидности методики. В оригинальном исследовании Форсайта получены связи 0.22 и 0.18 для шкалы идеализма и релятивизма соответственно (Forsyth, 1980).

\section{Номологическая валидность икал $E P Q$}

Для проверки номологической валидности опросника, которая связана с оценкой теоретической осмысленности корреляций конструктов, была выстроена номологическая сеть между идеализмом, релятивизмом и конструктами, связанными с ценностной сферой человека, отраженная в гипотезах, которые сформулированы в теоретической части данной статьи. Матрица корреляционных связей между шкалами EPQ и PVQ-R2 представлена в таблице 5.

Приведенные данные соответствуют предсказаниям, зафиксированным в гипотезах, и тем самым свидетельствуют в пользу номологической валидности EPQ. Кроме того, были обнаружены не обозначенные в рамках номологической сети связи идеализма и релятивизма с ценностями сохранения. Они также согласуются с теоретическими положениями. Так, ценности сохранения в теории Ш. Шварца противопоставляются ценностям открытости изменениям, что объясняет, почему одни связаны с релятивизмом положительно, а другие - отрицательно. Прямая корреляция идеализма с ценностями сохранения может быть обусловлена тем, что они включают в себя такие ценности первого порядка, как конформизм и традиция, которые разделяют мотивационную основу с ценностью благожелательности.

\section{Обсуждение результатов}

Цель проведенного исследования заключалась в валидизации русскоязычной версии опросника этических позиций Д. Форсайта, т.е. носила исключительно инструментальный характер. Нами были проанализированы предыдущие исследования, которые показывают, что простая одноуровневая двухфакторная модель опросника плохо соответствует эмпирическим данным. 
Таблица 5

Корреляции между шкалами EPQ и PVQ-R2 (N = 136)

\begin{tabular}{|l|c|c|c|c|}
\hline & Идеализм & Релятивизм & M & SD \\
\hline Самостоятельность & 0.01 & $0.26^{* *}$ & 4.95 & 0.70 \\
\hline Стимуляция & 0.05 & $0.19^{*}$ & 4.40 & 0.95 \\
\hline Гедонизм & 0.06 & $0.20^{*}$ & 4.63 & 0.88 \\
\hline Достижение & 0.09 & 0.11 & 4.45 & 0.99 \\
\hline Власть & -0.16 & 0.05 & 3.33 & 0.97 \\
\hline Безопасность & 0.12 & -0.11 & 4.13 & 0.96 \\
\hline Конформизм & $0.32^{* *}$ & $-0.24^{*}$ & 3.49 & 1.05 \\
\hline Традиция & 0.10 & $-0.22^{*}$ & 3.02 & 1.23 \\
\hline Благожелательность & $0.30^{* *}$ & -0.12 & 4.90 & 0.80 \\
\hline Универсализм & $0.47^{* *}$ & -0.06 & 4.05 & 0.84 \\
\hline Открытость изменениям & 0.04 & $0.28^{* *}$ & 4.66 & 0.66 \\
\hline Самоутверждение & -0.03 & 0.13 & 4.22 & 0.71 \\
\hline Сохранение & $0.28^{* *}$ & $-0.21^{*}$ & 3.74 & 0.72 \\
\hline Самопреодоление & $0.54^{* *}$ & -0.14 & 4.19 & 0.63 \\
\hline \multicolumn{1}{|c|}{$M D$} & 33.61 & 33.53 & & \\
\hline & 6.58 & 6.85 & & \\
\hline
\end{tabular}

${ }^{*} p<0.05,{ }^{* *} p<0.01$.

Исследователи по-разному решали эту проблему: одни исключали из опросника пункты, пытаясь добиться соответствия между эмпирическими данными и теоретическими постулатами, другие модифицировали модель, вводя в нее новые факторы, например правдивость. Однако проверка этих альтернативных моделей на русскоязычной выборке показала, что без добавления в них ковариации ошибок они не достигают приемлемого уровня пригодности. Поэтому нами была предложена двухфакторная двухуровневая модель опросника, предполагающая многомерность ортогональных факторов Идеализм и Релятивизм. В ней фактор второго порядка Идеализм включает в себя два фактора первого порядка: Недопушение вреда и Забота о благе. Фактор второго порядка Релятивизм включает три фактора первого порядка: Относительность этических систем, Межличностный релятивизм и Допустимость лжи.

Двухуровневая модель обладает рядом преимуществ как перед оригинальной моделью Д. Форсайта, так и перед моделями Дэвиса и Цуи. Во-первых, по 
результатам конфирматорного факторного анализа, двухуровневая модель показывает отличное соответствие структуры опросника эмпирическим данным в отличие от оригинальной модели Д. Форсайта. Во-вторых, двухуровневая модель соответствует такому важному постулату теории этических позиций Д. Форсайта, как независимость идеализма и релятивизма, и не требует включения дополнительного фактора с неясным теоретическим обоснованием, как в модели Дэвиса с соавт. В-третьих, двухуровневая модель сохраняет весь перечень утверждений оригинального опросника (по 10 пунктов на каждую шкалу), не требуя его сокращения, как в модели Цуи с соавт. Таким образом, предложенная модель позволяет устранить противоречия и недостатки, выявленные предшествующими исследованиями с использованием EPQ

Проведенный психометрический анализ показал, что апробируемый опросник этических позиций обладает хорошей внутренней согласованностью, ретестовой надежностью, конвергентной, дискриминантной и номологической валидностью. Важно также отметить, что, хотя результаты конфирматорного анализа позволяют высказать предположение, что факторы идеализма и релятивизма имеют многомерный характер, окончательное решение этого вопроса требует дальнейшей теоретической и экспериментальной работы. В этом смысле мы согласны с Г. Айзенком, который утверждал, что «факторный анализ и другие психометрические техники полезны как pons asinorum, но сами по себе являются плохим проводником к истине» (Eysenck et al., 1992, p. 116). Именно по этой причине при описании психометрических характеристик мы ограничились основными факторами (идеализм и релятивизм).

Несмотря на инструментальный характер исследования, необходимо также сказать несколько слов по поводу теоретического статуса этических позиций. На наш взгляд, этические позиции, как и многие другие психологические конструкты, имеют диспозициональную природу, в силу этого они являются не причинами, а вероятностью поведения (Skinner, 1984; Райл, 2000; Фёдоров, 2007). С этой точки зрения мораль представляет собой специфическую систему поведения, управляемого правилами (Kurtines, 1984; Peláez, 2001), а этические суждения усваиваются посредством тех же процессов научения, что и остальное поведение?. Таким образом, идеализм и релятивизм, с нашей точки зрения, следует рассматривать как диспозиции, а опросник этических позиций - как инструмент их оценки, при этом ответы на пункты представляют собой не результат интроспективного анализа, а образцы поведения.

\section{Выводы}

1. Русскоязычная версия EPQ имеет двухфакторную структуру, в которой идеализм и релятивизм представляют собой ортогональные факторы второго уровня.

\footnotetext{
${ }^{7}$ Еце Аристотель отмечал, что добродетели не врожденны, а возникают благодаря обучению и привычке (1983, с. 78).
} 
2. Шкалы русскоязычной версии $\mathrm{EPQ}$ обладают хорошей ретестовой надежностью, внутренней согласованностью, конвергентной и дискриминантной валидностью.

3. Получены теоретически предсказанные связи между этическими позициями и ценностями, оцениваемыми при помощи PVQ-R2, опирающегося на теорию Ш. Шварца, что свидетельствует в пользу номологической валидности ЕРQ.

\section{Литература}

Аристотель. (1983). Никомахова этика. В кн. Аристотель, Сочинеяия (в 4 т., т. 4, с. 53-294). М.: Мысль.

Корнилова, Т. В., Корнилов, С. А., Чумакова, М. А., Талмач, М. С. (2015). Методика диагностики личностных черт «Темной триады»: апробация опросника Темная Дюжина. Психологииеский журнал, 36(2), 99-112.

Лемешко, Б. Ю., Лемешко, С. Б. (2008). Об устойчивости и мощности критериев проверки однородности средних. Измерительная техника, 9, 23-28.

Райл, Г. (2000). Понятие сознания. М.: Идея-Пресс.

Фёдоров, А. А. (2007). Стиль в психологии: деконструкция термина. Вестник Новосибирского государственного университета. Серия: Психология, 1(1), 26-31.

Ханин, Ю. Л. (1976). Шкала Марлоу-Крауна для исследования мотивации одобрения. Методическое писъмо. Л.: НИИ физической культуры.

Шварц, Ш., Бутенко, Т. П., Седова, Д. С., Липатова, А. С. (2012). Уточненная теория базовых индивидуальных ценностей: применение в России. Психология. Журнал Высшей иколы экономики, 9(2), 43-70.

Ссылки на зарубежные источники см. в разделе References после англоязыиного блока.

Приложение

\section{Опросник этических позиций}

Инструкция. Ниже приведен список общих утверждений. Каждое из них отражает широко распространенное мнение, и нет правильных или неправильных ответов. Возможно, вы не согласитесь с одними пунктами и согласитесь с другими. Нас интересует то, насколько вы согласны или не согласны с утверждениями подобного рода. Пожалуйста, внимательно прочитайте каждое утверждение. Затем отметьте степень своего согласия или несогласия, опираясь на следующую шкалу:

1 - полностью не согласен;

2 - не согласен;

3 - ни то, ни другое;

4 - согласен;

5 - полностью согласен 


\begin{tabular}{|c|c|c|c|c|c|}
\hline & $\begin{array}{l}\text { Полностью } \\
\text { не согласен }\end{array}$ & & & & $\begin{array}{c}\text { Полностью } \\
\text { согласен }\end{array}$ \\
\hline $\begin{array}{l}\text { 1. Человек должен убедиться, что его действия не } \\
\text { нанесут вреда другому человеку, пусть даже небольшого. }\end{array}$ & 1 & 2 & 3 & 4 & 5 \\
\hline $\begin{array}{l}\text { 2. Нельзя допускать, чтобы другому человеку грозила } \\
\text { опасность, независимо от того, насколько } \\
\text { незначительной она может быть. }\end{array}$ & 1 & 2 & 3 & 4 & 5 \\
\hline $\begin{array}{l}\text { 3. Существование потенциального вреда для других } \\
\text { людей всегда безнравственно, независимо от того, какие } \\
\text { выгоды это сулит. }\end{array}$ & 1 & 2 & 3 & 4 & 5 \\
\hline $\begin{array}{l}\text { 4. Никто и никогда не должен наносить другому } \\
\text { психологический или физический вред. }\end{array}$ & 1 & 2 & 3 & 4 & 5 \\
\hline $\begin{array}{l}\text { 5. Человек должен воздерживаться от поступка, который } \\
\text { может каким-либо образом угрожать достоинству и } \\
\text { благополучию другого человека. }\end{array}$ & 1 & 2 & 3 & 4 & 5 \\
\hline $\begin{array}{l}\text { 6. Если поступок может навредить невинному человеку, } \\
\text { его не следует совершать. }\end{array}$ & 1 & 2 & 3 & 4 & 5 \\
\hline $\begin{array}{l}\text { 7. Решать, совершать поступок или не совершать, } \\
\text { сопоставляя его позитивные и негативные последствия, } \\
\text { безнравственно. }\end{array}$ & 1 & 2 & 3 & 4 & 5 \\
\hline $\begin{array}{l}\text { 8. Достоинство и благополучие людей должны быть } \\
\text { главной заботой в любом обществе. }\end{array}$ & 1 & 2 & 3 & 4 & 5 \\
\hline $\begin{array}{l}\text { 9. Никогда нет необходимости жертвовать } \\
\text { благополучием других. }\end{array}$ & 1 & 2 & 3 & 4 & 5 \\
\hline $\begin{array}{l}\text { 10. Нравственными поступками являются те, которые } \\
\text { точно соответствуют идеалам самого совершенного } \\
\text { поступка. }\end{array}$ & 1 & 2 & 3 & 4 & 5 \\
\hline $\begin{array}{l}\text { 11. Нет таких этических принципов, которые настолько } \\
\text { важны, что должны быть частью любого этического } \\
\text { кодекса. }\end{array}$ & 1 & 2 & 3 & 4 & 5 \\
\hline $\begin{array}{l}\text { 12. То, что является этичным, меняется в зависимости от } \\
\text { общества и ситуации. }\end{array}$ & 1 & 2 & 3 & 4 & 5 \\
\hline $\begin{array}{l}\text { 13. Моральные нормы нужно воспринимать так, словно } \\
\text { они являются индивидуальными: что один человек } \\
\text { считает нравственным, другой человек может считать } \\
\text { безнравственным. }\end{array}$ & 1 & 2 & 3 & 4 & 5 \\
\hline $\begin{array}{l}\text { 14. Разные системы моральных принципов нельзя } \\
\text { сравнивать по степени их правильности. }\end{array}$ & 1 & 2 & 3 & 4 & 5 \\
\hline $\begin{array}{l}\text { 15. На вопросы о том, что этично для всех людей, } \\
\text { никогда не найдут ответов, так как то, что нравственно и } \\
\text { безнравственно, зависит от конкретного человека. }\end{array}$ & 1 & 2 & 3 & 4 & 5 \\
\hline $\begin{array}{l}\text { 16. Моральные нормы - это просто личные правила, } \\
\text { которые указывают, как должен вести себя человек, и их } \\
\text { нельзя применять для оценки других. }\end{array}$ & 1 & 2 & 3 & 4 & 5 \\
\hline
\end{tabular}




\begin{tabular}{|c|c|c|c|c|c|}
\hline & $\begin{array}{l}\text { Полностью } \\
\text { не согласен }\end{array}$ & & & & $\begin{array}{c}\text { Полностью } \\
\text { согласен }\end{array}$ \\
\hline $\begin{array}{l}\text { 17. Этические суждения в межличностных отношениях } \\
\text { настолько сложны, что людям нужно разрешить } \\
\text { формулировать их собственные индивидуальные } \\
\text { кодексы. }\end{array}$ & 1 & 2 & 3 & 4 & 5 \\
\hline $\begin{array}{l}\text { 18. Жесткая этическая позиция, которая запрещает } \\
\text { определенные виды поступков, препятствует } \\
\text { достижению лучших отношений между людьми и их } \\
\text { приспособлению друг к другу. }\end{array}$ & 1 & 2 & 3 & 4 & 5 \\
\hline $\begin{array}{l}\text { 19. Нельзя сформулировать ни одно правило касательно } \\
\text { лжи: то, допустима или не допустима ложь, целиком } \\
\text { зависит от ситуации. }\end{array}$ & 1 & 2 & 3 & 4 & 5 \\
\hline $\begin{array}{l}\text { 20. Считать ложь безнравственной или нравственной, } \\
\text { зависит от обстоятельств, связанных с поступками. }\end{array}$ & 1 & 2 & 3 & 4 & 5 \\
\hline
\end{tabular}

\title{
Ключ:
}

Идеализм: 1, 2, 3, 4, 5, 6, 7, 8, 9, 10

Релятивизм: 11, 12, 13, 14, 15, 16, 17, 18, 19, 20

Фёдоров Александр Александрович - заведующий кафедрой, кафедра клинической психологии, Институт медицины и психологии, Новосибирский государственный университет, кандидат психологических наук.

Сфера научных интересов: философия и история психологии, современный бихевиоризм, психология морального поведения.

Контакты: fedleks@yandex.ru

Бадиев Игорь Валерьевич - старший преподаватель, кафедра возрастной и педагогической психологии, Бурятский государственный университет.

Сфера интересов: психология характера, теория психологии.

Контакты: bad_igor@mail.ru

\section{Validation of the Russian-Language Version of the Ethics Position Questionnaire}

\author{
A.A. Fedorov ${ }^{\mathrm{a}}$, I.V. Badiev
}

${ }^{a}$ Novosibirsk State University, 1 Pirogova Str., Novosibirsk, 630090, Russian Federation

${ }^{b}$ Buryat State University, 24 a Smolina Str., Ulan-Ude, 670000, Russian Federation

\begin{abstract}
The results of validation of the Russian version of D.R. Forsyth's Ethics Position Questionnaire (EPQ) are presented. The original version of the questionnaire contains two orthogonal factors (idealism and relativism) that form the basis of taxonomy of ethical positions
\end{abstract}


(situationism, absolutism, subjectivism and exceptionism). The article suggests that idealism and relativism should be considered as behavioral dispositions. In this study, several theoretical models have been verified by means of confirmatory factor analysis. The CFA revealed that a twolevel structural model where idealism and relativism are orthogonal second-order factors has the best fit. Idealism includes such factors as focus on reducing harm (I1) and concern for good (I2), and relativism includes such factors as relativity of ethic systems (R1), interpersonal relativism (R2) and veracity (R3). The received model has a number of advantages. First, it fully corresponds to the theoretical model of D. R. Forsyth, including the orthogonality of the main factors. Secondly, it assumes the multidimensionality of the constructs "idealism" and "relativism." Thirdly, it allows to reconcile the results of previous empirical studies. The research established that the EPQ has good internal consistency, test-retest reliability, convergent, discriminant and nomological validity. The latter was evaluated within the nomological network in which idealism and relativism were correlated with constructs associated with the value system (within the Sh. Schwartz theory of basic values). The results make it possible to consider the Russian version of the EPQ as a reliable and valid instrument of assessment of idealism and relativism.

Keywords: ethics positions, idealism, relativism, morality, disposition.

\section{References}

Aristotle. (1983). Nikomakhova etika [Nicomachean Ethics]. In Aristotle, Collected works (Vol. 4, pp. 53-294). Moscow: Mysl'.

Campbell, D. R., \& Fiske, D. W. (1959). Convergent and discriminant validation by the multitraitmultimethod matrix. Psychological Bulletin, 56(2), 81-105.

Cui, C. C., Mitchell, V., Schlegelmilch, B. B., \& Cornwell, B. (2005). Measuring consumers' ethical position in Austria, Britain, Brunei, Hong Kong, and USA. Joumal of Business Ethics, 62(1), 5771. doi: $10.1007 / \mathrm{s} 10551-005-8501-7$

Davis, M. A., Andersen, M. G., \& Curtis, M. B. (2001). Measuring ethical ideology in business ethics: A critical analysis of the Ethics Position Questionnaire. Joumal of Business Ethics, 32(1), 35-53. doi:10.1023/A:1010701417165

Douglas, P. C., \& Wier, B. (2005). Cultural and ethical effects in budgeting systems: A comparison of U.S. and Chinese managers. Joumal of Business Ethics, 60(2), 159-174. doi:10.1007/s10551-004-6711-z

Dunn, T. J., Baguley, T., \& Brunsden, V. (2014). From alpha to omega: A practical solution to the pervasive problem of internal consistency estimation. British Journal of Psychology, 105(3), 399412. doi:10.1111/bjop.12046

Eysenck, H. J., Barrett, P., Wilson, G., \& Jackson, C. (1992). Primary trait measurement of the 21 components of the P-E-N system. European Joumal of Psychological Assessment, 8(2), 109-117.

Fedorov, A. A. (2007). Stil' v psikhologii: dekonstruktsiia termina [Style in psychology: Deconstruction of the term]. Vestnik Novosibirskogo Gosudarstvennogo Universiteta. Seriya Psikhologiya, 1(1), 26-31. (in Russian)

Fornell, C., \& Larcker, D. F. (1981). Evaluating structural equation models with unobservable variables and measurement error. Journal of Marketing Research, 18(1), 39-50. doi: $10.2307 / 3151312$ 
Forsyth, D. R. (1980). A taxonomy of ethical ideologies. Joumal of Personality and Social Psychology, 39(1), 175-184. doi:10.1037/0022-3514.39.1.175

Forsyth, D. R., O'Boyle, E. H., \& McDaniel, M. A. (2008). East meets West: A meta-analytic investigation of cultural variations in idealism and relativism. Joumal of Business Ethics, 83(4), 813-833. doi:10.1007/s10551-008-9667-6

Geldhof, G. J., Preacher, K. J., \& Zyphur, M. J. (2014). Reliability estimation in a multilevel confirmatory factor analysis framework. Psychological Methods, 19(1), 72-91.

Hair, J. F., Black, W. C., Babin, B. J., \& Anderson, R. E. (2014). Multivariate data analysis. Harlow, UK: Pearson Education Limited.

Hermida, R. (2015). The problem of allowing correlated errors in structural equation modeling: concerns and considerations. Computational Methods in Social Sciences (CMSS), 3(1), 5-17.

Hu, L., \& Bentler, P. M. (1999). Cutoff criteria for fit indexes in covariance structure analysis: Conventional criteria versus new alternatives. Structural Equation Modeling: A Multidisciplinary Journal, 6(1), 1-55. doi:10.1080/10705519909540118

Karande, K., Rao, C. P., \& Singhapakdi, A. (2002). Moral philosophies of marketing managers: A comparison of American, Australian, and Malaysian cultures. European Joumal of Marketing, 36(7/8), 768-791. doi:10.1108/03090560210430791

Khanin, Yu. L. (1976). Shkala Marlou-Krauna dlya issledovaniya motivatsii odobreniya. Metodicheskoe pis'mo [Marlowe-Crowne Social Desirability Scale]. Leningrad: NII fizicheskoi kul'tury. (in Russian)

Kornilova, T. V., Kornilov, S. A., Chumakova, M. A., \& Talmach, M. S. (2015). The Dark Triad personality traits measure: approbation of the Dirty Dozen Questionnaire. Psikhologicheskii Zhumal, 36(2), 99-112. (in Russian)

Kurtines, W. M. (1984). Moral behavior as rule-governed behavior: A psychosocial role-theoretical approach to moral behavior and development. In Morality, moral behavior, and moral development (pp. 149-194). New York: Wiley.

Lemeshko, B. Yu., \& Lemeshko, S. B. (2008). Ob ustoichivosti i moshchnosti kriteriev proverki odnorodnosti srednikh [On the stability and power of criteria for checking the homogeneity of means]. Izmeritel'naia Tekhnika, 9, 23-28. (in Russian)

Marsh, H. W., Hau, K.-T., \& Wen, Z. (2004). In search of Golden Rules: Comment on hypothesistesting approaches to setting cutoff values for fit indexes and dangers in overgeneralizing Hu and Bentler's (1999) findings. Structural Equation Modeling: A Multidisciplinary Journal, 11(3), 320 341. doi:10.1207/s15328007sem1103_2

Norman, G. (2010). Likert scales, levels of measurement and the 'laws' of statistics. Advances in Health Sciences Education, 15(5), 625-632. doi:10.1007/s10459-010-9222-y

Paulhus, D. L. (1991). Measurement and control of response bias. In J. P. Robinson, P. R. Shaver, \& L.S. Wrightsman (Eds.), Measures of social psychological attitudes (Vol. 1, pp. 17-59). San Diego, CA: Academic Press.

Peláez, M. (2001). Morality as a system of rule-governed behavior and empathy. Behavioral Development Bulletin, 10(1), 8-14. doi:10.1037/h0100475

Redfern, K. (2004). An empirical investigation of the Ethics Position Questionnaire in the People's Republic of China. Journal of Business Ethics, 50(3), 199-210. doi:10.1023/B:BUSI.0000024741.85399.0d

Revelle, W., \& Zinbarg, R. E. (2008). Coefficients Alpha, Beta, Omega, and the glb: Comments on Sijtsma. Psychometrika, 74(1), 145-154. doi:10.1007/s11336-008-9102-z 
Revilla, M. A., Saris, W. E., \& Krosnick, J. A. (2014). Choosing the number of categories in AgreeDisagree Scales. Sociological Methods and Research, 43(1), 73-97. doi:10.1177/0049124113509605

Robertson, C. J., Gilley, K. M., \& Street, M. D. (2003). The relationship between ethics and firm practices in Russia and the United States. Joumal of World Business, 38(4), 375-384. doi:10.1016/j.jwb.2003.08.022

Ryle, G. (2000). Ponyatie soznaniya [The concept of mind]. Moscow: Ideia-Press. (in Russian; transl. of: Ryle, G. (1946). The concept of mind. New York: Barnes \& Noble.

Satorra, A., \& Bentler, P. M. (1994). Corrections to test statistics and standard errors in covariance structure analysis. In Latent variables analysis: Applications for developmental research (pp. 399419). Thousand Oaks, CA: Sage.

Schwartz, S., Butenko, T. P., Sedova, D. S., \& Lipatova, A. S. (2012). A refinined theory of basic personal values: validation in Russia. Psychology. Joumal of Higher School of Economics, 9(2), 4370. (in Russian)

Skinner, B. F. (1984). Representations and misrepresentations. Behavioral and Brain Sciences, 7(4) 655-667. doi:10.1017/S0140525X00027989

Sommer, S., Welsh, D., \& Gubman, B. (2000). The ethical orientation of Russian entrepreneurs. Applied Psychology, 49(4), 688-708. doi:10.1111/1464-0597.00040

Alexandr A. Fedorov - associate professor, head, Section of Clinical Psychology, Institute of Medicine and Psychology, Novosibirsk State University, Ph.D.

Research area: philosophy and theory of psychology, contemporary behaviorism, psychology of moral behavior.

E-mail: fedleks@yandex.ru

Igor V. Badiev - senior lecturer, Buryat State University.

Research area: psychology of character, theory of psychology, psychology of moral behavior.

E-mail: bad_igor@mail.ru 